\title{
Designing Management Control Systems: Systemic vs Sectoral Approach
}

\author{
Paolo Popoli ${ }^{1}$ \\ ${ }^{1}$ Parthenope University of Naples, Naples, Italy \\ Correspondence: Paolo Popoli, Parthenope University of Naples, Department of Management Studies and \\ Quantitative Methods, Via Generale Parisi 13, Naples, Italy. E-mail: paolo.popoli@uniparthenope.it
}

Received: November 182018

Accepted: March 8, 2019

Online Published: May 16, 2019

doi:10.5539/ijbm.v14n6p130

URL: https://doi.org/10.5539/ijbm.v14n6p130

\begin{abstract}
Management control systems are increasingly called upon to find an appropriate balance between efficiency and flexibility, between short- and long-term orientation, between formal and informal tools and techniques. However, management control has been studied and treated, in the prevailing literature, by adopting a "sectoral" approach. In this respect, economic-financial control, organizational control, and strategic control are deeply analyzed and clearly qualified in their respective aims, methodology and tools, but at the same time are the results of a specialized and fragmented perspective. Starting from these premises, this paper aims to provide a conceptual framework for designing a management control system from a "systemic perspective", in order to capture all economic, financial, strategic and operational dimensions of business within a unitary management control system. Methodologically, this paper is conceptual in nature, based on a qualitative analysis of the prevailing literature, aimed at providing advanced insights on this field and bases for further theoretical and empirical studies. In particular, after discussing the most significant stages in the evolution of management control systems over the last decades, this paper highlights the importance and advantages of adopting a systemic approach that facilitates a unitary management control system wherein the numerous and different dimensions of management are considered interdependent, in order to achieve an integrated equilibrium between efficiency and effectiveness, between short- and long-term performances, and to unify strategic and operational management.
\end{abstract}

Keywords: Management control, systemic approach, performance measurement, value creation

\section{Introduction}

Management control has been studied according to various management profiles and, in most cases, it has been analyzed by adopting a "sectoral" approach (Bin-Nashwan, Abdullah, \& Obaid, 2017). In this respect, economic-financial control, organizational control, and strategic control are deeply analyzed and clearly qualified in their respective aims, methodology and tools but, at the same time, they are the results of sectoral approaches that have been favored in studies (Anthony, 1965, 1990). On the other hand, less attention has been devoted by scholars to the study of control activity from a systemic perspective that would make it possible to integrate and balance the various dimensions of management within a "unitary control system."

Moreover, the emphasis placed on the multiple configurations of the control activity is justified by considering the fact that the logic of management, too, has been traditionally defined, with a marked sectoral approach, for specific "areas" or "functions," and was only then, but often barely, subjected to a process of recomposition ad unum not always focused or, to be more precise, not always qualified. More recently, studies on business management have clearly considered the "systemic approach" the most appropriate method to carry on studies of the company and the interpretation of management (Golinelli, 2000), by intensifying efforts toward understanding the interdependencies between functions and management processes, modalities, and criteria by which the company relates to the external environment; in other words, by observing the company as a whole rather than as a set of different components.

In this study, the management control system is analyzed in evolutionary perspective, starting from a formulation that one can call "traditional" to reach more "developed" approaches, in the sense of a greater correspondence by the control requirements under complexity and dynamism of the external and internal environment to the enterprise (Pekkola, Saunila et al., 2016). According to Tucker, Thorne and Gurd (2009), the picture presented in the literature regarding the relationship between management control systems, strategy and organizational 
performance has been quite incomplete until the last decade, because this relationship remained largely unexplored, little documented or understood.

This transition from traditional to more developed approaches is because since the 1970 s, control systems had to face new logic and principles of management, highly different from those theorized by Taylor and that characterized Ford (Duncan 1976; Naro, 1998; Simons, 1995). We can note that the responses provided by the control of the renewal requirements may be of two different types (Figure 1):

- Development of new forms of control, specifically strategic control and organizational control according to an approach that can be called "sectoral" on the basis of the object of control (variables and time horizon).

- Improvement of management control by valuing the strategic and organizational dimensions according to an approach that can be called "systemic," with a view to the uniqueness of the company system.

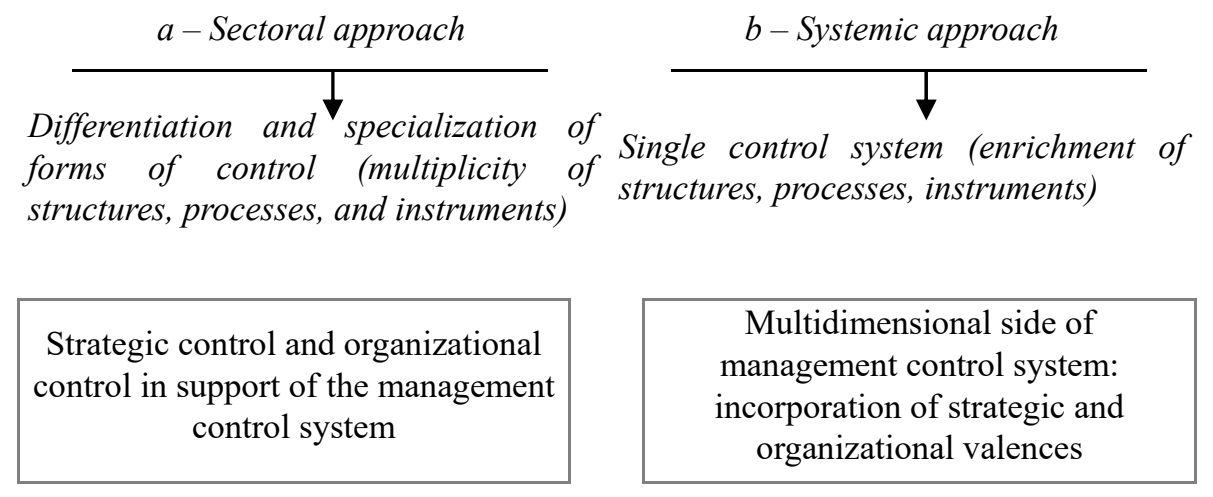

Figure 1. Evolution of the management control following two different guidelines

In light of the renewed interest aroused by the systemic approach in the studies conducted on the company, the present study proposes to place the control activity within a unitary vision of the company, by proposing a conceptual model of the management control system. This model incorporates the multidimensional nature of company management as part of a "unitary" system and reflects, in terms of structure, processes, and tools, the impossibility of splitting between the operational moment and the strategic moment, between short- and long-term management, and between effectiveness and efficiency.

\section{Requirements of Management Control in the Era of Complexity}

The following elements have changed the logic of a company from the past and therefore represent the new challenges for control systems: evolution of the external environment, organizational characteristics of companies, increasing value of intangible inputs and outputs, expansion of the infra- and inter-relational framework of company organization, reconsideration of management activities from a process perspective. These elements are called upon to be consistent with the logic of value creation, in the broad sense of "global value created," a synthesis of the value created with respect to the various categories of stakeholder (not only customers, shareholders, employees, and actors in the competitive system but also subjects, institutions, and social aggregates that complete the relational framework of the company) (Bititci et al., 2012; Donaldson \& Preston, 1995).

Considering the value created for stakeholders necessarily implies redefining the management control system around the activities and processes of the company that stands out for the purpose of determining the various value dimensions, instead of a configuration based on the "single functions" vertically identifiable.

A management control system must also facilitate the organization, production, and acquisition of knowledge, empowering organizational learning processes (Barthélemy \& Doublet, 2009; Bouquin, 2005; Nguyen et al., 2017). To this end, every individual must become author of learning processes; moreover, on the one hand, it is important to adopt a responsible work attitude inspired by cohesion, trust, loyalty, and commitment; on the other hand, it is necessary for the learning process to be supported by systems of encouragement, career, and remuneration, monetary or non-monetary, closely linked to the quality of the work activity carried out and the results obtained (Cardinal, Sitkin, \& Long, 2004).

Finally, in recent years numerous scholars have been considering unsatisfactory to maintain different systems of control, bringing out the opposite requirement of a unitary vision in the construction of the management control 
system (Johnson and Kaplan, 1987a, 1987b; Gumb, 2011).

A priority requirement for management control in highly complex environments (characterized by large variety and high variability of phenomena) is to release the control system from the accounting matrix in order to expand toward "the multidimensional side" of the company results in evaluation (Ansoff, 1979; Lorino, 2001).

In an environment where the variables on which the competitive success of the company depends are numerous and differentiated in nature, it is not sufficient to refer only to the economic and financial performances. By drawing attention to the many shortcomings of traditional management control systems, Johnson and Kaplan (1987a; 1987b) pointed out that there are often all kinds of qualitative indicators that better express a company's performance than the monthly or quarterly income. As a result, it is important to complement traditional indicators of economic and financial nature with other parameters for evaluating the company's performance.

Moreover, it is the veritable concept of the "success" of the company itself that leads to the need to adopt a multidimensional approach toward evaluating the results obtained by the company; this approach is based on three different aspects (Popoli, 2002; Meyssonnier \& Rasolofo-Distler, 2008, 2011):

- Economic and financial,

- Competitive,

- Social.

It seems obvious that the concept of the company's "success" may not coincide with the economic and financial results it has obtained. Therefore, this means extending the "measurement" activity to a set of internal and external variables which are not captured by the accounting instruments, whereas they are directly linked to factors determining the company's success (Naro \& Travaillé, 2011; Trébucq, 2011; Dilhani, Arachchilage \& Smith, 2013). From this point of view, it can be said that the company's strategy and the "critical success factors" constitute the starting point in programming the system of parameters and indicators, thus making the control instruments congruent with the specific and contingent situation of the company (Rockart, 1979).

At this stage, clearly, the multidimensional nature of the indicators is merely a reflection of the multidimensional nature of the critical success factors; similarly, it is obvious that the exclusive reference to economic and financial indicators leaves many of the management variables from which the success or failure of the enterprise derives in the shadow and that cannot always be captured by accounting systems (Bhimani and Langfield-Smith, 2007; Kaplan, 2009; Kaplan and Norton, 1992).

\section{Guidelines for the Development of Management Control Systems}

The evolution of management control systems is closely linked to changes occurred both in the external environment and the internal organization, both of which have become increasingly complex (Golinelli, 2000). The consequent complexity of management, coming from both internal and external factors, has gradually required the development of the capacities of selective perception of the critical variables for the survival and development of the company, the causal relationships between the various variables, and the determinants of the results and possible deviations from the objectives, without forgetting the development of the intervention levers at the disposal of management to carry out the necessary processes of adaptation and control (Figure 2).

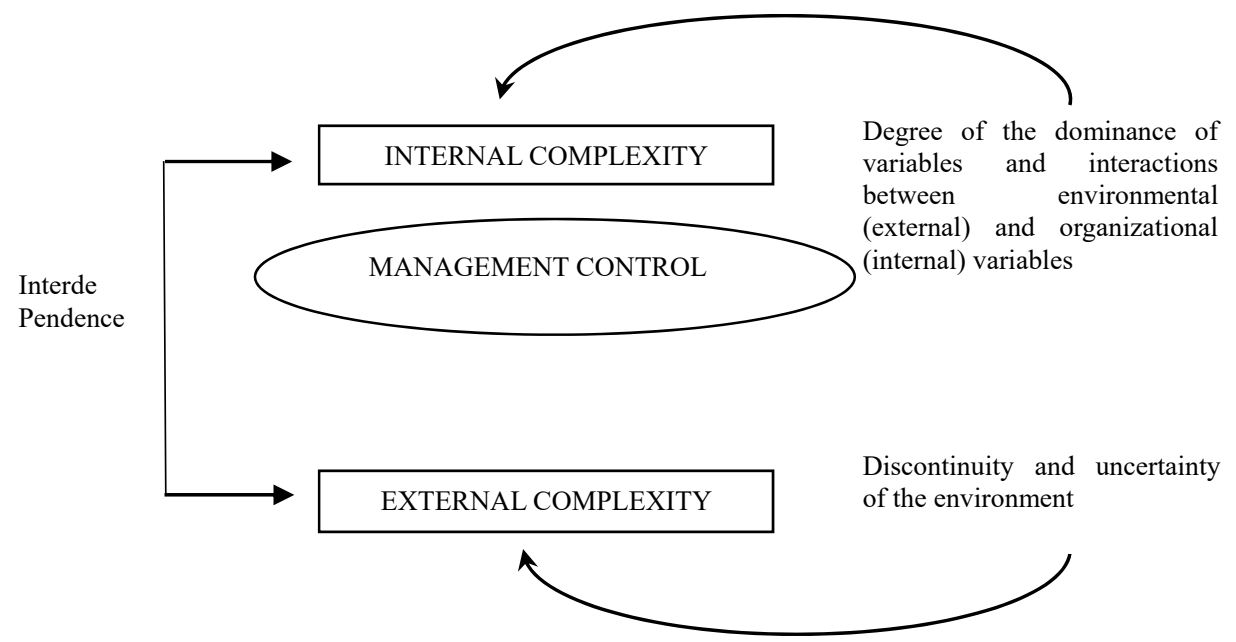

Figure 2. Consistency between control systems and level of management complexity (internal and external) 
With regard to the relationship between success variables and control systems, it is intuitive that when the key success factors lead to improved efficiency (standardization of production processes, achieving economies of scale, competition essentially centered on price), the preferred output of control systems is to guide the company toward the best combination of production factors, toward cost reduction, and toward the correct determination of standards. Through this, the technical-accounting system of control directed toward quantifying and monetizing management phenomena and their correlation with the formation of the company's income becomes an indispensable element for obtaining the key success factor focused on efficiency.

In completely different situations, where the external environment makes efficiency-centered business conduct extremely dangerous, the key variables of success increasingly concern the modalities of business-environment interaction, distinctive capabilities, acquisition and expansion of intangible assets, and the ability to introduce the time factor into strategic variables and into the operational program of activities (Asiaei and Jusoh, 2017).

At the same time, new concepts and approaches are emerging in studies on management control, with increasing attention to medium- and long-term management requirements. In this context, new conceptions, whether of control systems understood as a whole or of the instruments they use, are gradually emerging (Kasurinen, 2002; Alcouffe et al., 2008; Lenz and Hahn, 2015). This makes the budget a flexible instrument, which also incorporates a feedback-forward logic alongside the traditional one of feedback, in order to fulfill a "constructive and forward-looking" steering function (Newman, 1975). The technical-accounting structure is not observed as much in its capacity to produce data and information, valid in itself, as in its capacity to produce the desired organizational behavior (Holfstede, 1970; Hopwood, 1974); moreover, the construction of the budget knows the zero-based budget technique (Phyrr, 1973).

However, much of literature consider that the progress made in the field of traditional instruments and forms of control is not sufficient to effectively adapt control systems to new requirements (Abernethy and Brownell, 1999). This makes it necessary to find new, more developed forms of control, essentially directed toward the company-environment relations management; as consequence, strategic control appears, shifting the focus from output control to input control (Lorange et al., 1986).

The North American and Anglo-Saxon literature, more inclined to a "sectoral" than a systemic approach in control systems, significantly impacted the development of strategic control as an additional and superior form, in the hierarchy of controls, to that of management. The strategic control guideline derives as a typology of control separate from the management control, the thesis being that there remain significant differences between the two forms in terms of logic and purposes (Bititci et al., 2000). As will be observed further, this approach has been criticized by most of scholars, the basic idea being that strategic moment and operational moment of management cannot be separated as different and independent moments, according to a unitary approach to business management (Bergamin Barbato, 1991).

At the same time, other scholars have focused on the organizational dimension of control processes, structure, and instruments. In this evolving guideline of thought, they have tried to provide an adequate response to the need to develop operational mechanisms capable of conditioning and stimulating the adoption of organizational behaviors consistent with the complex goals of the company. This was formulated into the "organizational control" with meanings that find application in a great variety of fields involving the whole organization and all its variables (structure, people, and management process) (Flamholtz, 1987).

\section{From the Multiplicity of Controls to the Unitary System of Management Control}

The unitary and multidimensional vision of management control that we want to achieve in this study is based on the logical basis in the search for the consideration and valorization of all the valences of control by seeking the greatest integration of the forms of control within a unitary system of management control.

The basis on which it is possible to build this new theoretical framework must be sought, in our opinion, in the "logic of balances" that includes various aspects of company management and indirectly various operational mechanisms that operate within it, including control.

Reasoning in terms of the "logic of balances" means avoiding excessive focus on particular aspects or mechanisms of the control system. The "logic of balances" is essentially the result of the idea that in the company management context and indirectly in the control system context, it is not useful and, in some cases, not possible to make such a clear distinction between:

- Strategic management and operational management,

- Behavioral aspects and rational-deterministic aspects of management. 


\subsection{Strategic Management and Operational Management}

In today's contexts, it is neither possible in a management activity to separate strategic content from operational content nor to imagine a division of tasks that would identify those of a strategic nature and assign them an identifiable and authoritative role in the company, then assigning operational tasks to lower levels of the organizational hierarchy. Such an approach faces a reality that does not lend itself to being approached by successive approximations (first the strategic moment and then the operational activities) but which, to the extent that it is highly dynamic and unpredictable, requires global responses based on interdependencies rather than on logical sequences of management.

According to the most recent studies, "strategic management" represents a "global approach to management" that combines strategic and operational management, avoiding the idea that strategy becomes an abstract design, anyway detached from the daily life of any company.

In each decision and operational activity, there is a strategic dimension which, if neglected, would amount to a state of "management myopia" with the inevitable effect of making them "neutral" in relation to the strategy (Shank and Govindarajan, 1989), trapping them in repetitive patterns of operations whose functionality and consistency with strategies are only evaluated ex-ante at the time of programming.

\subsection{Behavioral Aspects and Rational-Deterministic Aspects of Management}

The second area of the application of the logic of balances is the dual behavioral and rational-deterministic nature that characterizes a management control system.

Under the first aspect, management control has a strong organizational valence as it inevitably influences, directly or indirectly, the behavior of the operating workers in the company, through mechanisms such as distribution of responsibilities, setting of objective parameters, and analysis of variances and their connection with other operational systems (for example the bonus and reward system) (Burland et al., 2004).

Under the second aspect, management control unquestionably introduces a dimension of "rationality" and "determinism" into the decision-making process. Rationality instruments such as rules and procedures represent in all cases a defense of order in the organization, integrity of the structure, and coordination between workers and activities. Their absence may introduce uncertainty into the organization; in this regard, Cafferata (2014) observed that "internal disorder, i.e., the absolute or relative lack of structural characters, such as bureaucratic, creates a dysfunction to pursue the goals of the organization."

This being said, the two dimensions (economic rationality and behavioral aspects) coexist in a relationship of close interdependence, in any action or decision in which the man is an actor, by combining in various doses according to specific circumstances, but without canceling each other out.

As observed by Hax and Majluf (1991), the company's performance is the result of a combination of formal analytical factors (hard) and behavioral factors (soft) that coexist in the management of the company. The authors identify a strategic management model that pays balanced attention to both the formal aspect of the organization (role structure and work tasks) and the analytical tools used to reduce management uncertainty, both informal and behavioral.

\section{Discussion: Toward a Unitary and Multidimensional Control System}

From the considerations developed so far, we can deduce the following implications in terms of control:

- The control system must adequately support strategic management by taking into account all dimensions of efficiency and effectiveness - short, medium, and long term, and both formalism (rationality) and non-formalism (behavior) through which strategic management is specifically represented in the specific company,

- Strategic control, organizational control, and operational control are the result of a schematization of management issues that has lost its interpretative validity for the company's management and its ability to face uncertainty and internal and external complexity; the three forms of control must be combined in a unitary system.

At this stage, it is possible to explain that the expression "unitary management control system" is intended at identifying a "unique" control system that contains the multidimensional aspects: strategic, organizational and operational. Therefore, not several and separate forms of control but a unitary system that monitors operations, decisions, products, or services under the following profiles:

- Efficiency and effectiveness, 
- Impact on short-, medium-, and long-term economic and financial conditions,

- Functional or dysfunctional role in relation to the internal organizational balances (various conditions different from those that are economical and financial) and in relation to the strategic identity of the company.

The vision of management control as a unique system of management control that incorporates strategic, organizational, and operational valences stems from the fact that it is not appropriate to consider strategic control as an additional and different mechanism to operational control, but both must coexist within a unique control system.

Considering that the distinction between strategic and operational management is no longer acceptable given the penetration exerted by the influx of the external environment on more and more parts of the company to the point of not being able to identify parties who are not involved means, therefore, to reject the idea that there can be a strategic control different from management control. Strategic control is a "management philosophy" rather than a new type of control, which is added to the more traditional and consolidated ones. It represents a basic spirit able of permeating the company's action, which leads to the monitoring of the gradual process according to the striking strategic dimensions and to the possible modification of the strategy on the basis of this evaluation. Therefore, it is the management tool for not only major changes in the company but also the impact of small day-to-day decisions on strategic choices.

\section{Conclusion}

In the past, the idea of management control as a mechanism to optimize the use of resources to achieve predefined strategic objectives has given the idea of being able to associate "strategy" with the long-term and "control" with the short-term.

In the reality of current contexts, it is no longer theoretically legitimate to retain that management takes place through a successive disaggregation of general objectives into partial objectives, from strategic decisions to operational decisions, according to the most traditional sequential logic.

Operating in turbulent, complex, and highly dynamic environments, the need for rapid adjustments and continuous verification of the validity of objectives creates an interconnection between the two moments, and this validity does not lend itself to a translation into the sequential process. Therefore, the distinction between the time when the company's objectives are set and the time when the actions aimed at achieving them take place loses its raison d'être; it is no more acceptable to distinguish a medium and long-term management approach and a short-term approach (the first supported by strategic planning and the latter by management control).

Hence, there is a need to design a unique management control system in which both the definition of the objectives to be achieved and the management of the activities necessary to achieve them are accommodated in the object of the control, in the programming criteria, in the technical and accounting instruments, and in the other components of the management information system.

In conclusion, the unique management control system represents a theoretical outline that reflects the concept of management uniqueness and its character of not being separable into various phases.

The unitary control system is developed on the following logical basis: the various management requirements (efficiency and effectiveness, from short-, medium-, and long-term perspectives) cannot be tackled with "specialized" control systems but must be comprehended within a unitary approach to control, projected in all its components with a view to "balancing" between opposing pressures.

The success of the company is certainly related to not only the formulation of the strategy but also the implementation of the strategy as a result of the succession of coherent, interdependent decision-making acts, the effects of which are exerted on all management dimensions: short-, medium-, and long-term efficiency and effectiveness.

\section{References}

Abernethy, M. A., \& Brownell, P. (1999). The role of budgets in organizations facing strategic change: an exploratory study. Accounting, Organizations and Society, 24(3), 189-204. https://doi.org/10.1016/S0361-3682(98)00059-2

Alcouffe, S., Berland, N., \& Levant, Y., (2008). "Succès" et "échec" d'un outil de gestion: le cas de la naissance des budgets et de la gestion sans budget. Revue Française de Gestion, 34(188), 291-306.

Ansoff, I. H. (1979). Strategic Management. London: McMillan. 
Anthony, R. N. (1965). Planning and control systems. Boston: Harvard Business School Press.

Anthony, R. N. (1990). Le control directionnel. Italy, Milan: F. Angeli Ed.

Asiaei, K., \& Jusoh, R. (2017). Using a robust performance measurement system to illuminate intellectual capital. International Journal of Accounting Information Systems, 26, 1-19. https://doi.org/10.1016/j.accinf.2017.06.003

Barthélémy, J., \& Doublet, J. M. (2009). Quelques enseignements de la crise. Revue Française de Gestion, 193(3), 13-14.

Bergamin Barbato, M. (1991). Programmazione e controllo in un'ottica strategica. Italy, Torino: Utet.

Bhimani, A., \& Langfield-Smith, K. (2007). Structure, formality and the importance of financial and non-financial information in strategy development and implementation. Management Accounting Research, 18, 3-31. https://doi.org/10.1016/j.mar.2006.06.005

Bin-Nashwan, S. A., Abdullah, N. S., \& Obaid, M. M. (2017). A review of literature in management control system (MCS), business strategy, and firm's performances. International Journal of Management Research \& Review, 7(4), 99-112.

Bititci, U. S., Garengo, P., Dorfler, V., and Nudurupati, S. (2012). Performance measurement: Challenges for tomorrow. International Journal of Management Reviews, 14(3), 305-327. https://doi.org/doi.org/10.1111/j.1468-2370.2011.00318.x

Bititci, U. S., Turner, T., \& Begemann, C. (2000). Dynamics of performance measurement systems. International Journal of Operations \& Production Management, $20(6), \quad 692-704$. https://doi.org/doi.org/10.1108/01443570010321676

Bouquin, H. (2005). Les fondements du contrôle de gestion. France: Presses Universitaires de France.

Burlaud, A., Teller, R., Chatelain-Ponroy, S., Mignon S., \& Walliser, E. (2004). Contrôle de gestion. Vuibert.

Cafferata, R. (2014). Management in adattamento. Italy, Bologne: Il Mulino.

Cardinal, L. B., Sitkin, S. B., \& Long, C. P. (2004). Balancing and rebalancing in the creation and evolution of organizational control. Organization $\quad$ Science, $411-431$. https://doi.org/doi.org/10.1287/orsc.1040.0084

Dilhani, N., Arachchilage, K., \& Smith, M. (2013). The effects of the diagnostic and interactive use of management control systems on the strategy-performance relationship. Journal of Applied Management Accounting Research, 11(1), 9-27.

Donaldson, T., \& Preston, L. (1995). The stakeholder theory of the corporation: concepts, evidence, and implications. Academy of Management Review, 20(1), 65-91. https://doi.org/doi.org/10.5465/amr.1995.9503271992

Duncan, R. B., (1976). The ambidextrous organization: designing dual structures for innovation. In R. H. Kilman, L. R. Pondy, \& D. Slevin (Eds.), The management of organization design (vol. 1). New York: North-Holland.

Flamholtz, E. G. (1987). How to make the transition from an entrepreneurship to a professionally managed firm. San Francisco: Jossey-Bass.

Golinelli, G. M. (2000). L'approche systemique pour le gestion de l'entreprise. Italy, Padova: Cedam.

Gumb B., Fressoz, P., \& Joannidès, V. (2011). Le theme de l'alignement dans les tableaux de bord strategiques: leçons tirées de la pratique. Revue Française de Gestion, 37(211), 119-130.

Hax, A. C., \& Majluf, N. S. (1991). The strategy concept and process. N.J: Prentice-Hall, Englewood Cliffs.

Hofstede, G. H. (1970). The game of budget control. Van Gorcum, Assen.

Hopwood, A. G. (1974). Accounting and human behaviour. Devon: Accountancy Age Books.

Johnson, H. T., \& Kaplan, R. S. (1987a). The rise and fall of management accounting. Management Accounting, n. January. https://doi.org/10.1109/EMR.1987.4306297

Johnson, H. T., \& Kaplan, R. S. (1987b). Relevance lost. The rise and fall of management accounting. Boston: Harvard Business School Press. 
Kaplan, R. S. (2009). Conceptual foundations of the balanced scorecard. In Chapman C. S., Hopwood A. G. (Eds.), Handbook of Management Accounting Research (pp. 1253-1269). https://doi.org/doi.org/10.1016/S1751-3243(07)03003-9

Kaplan, R. S., \& Norton, D. P. (1992). The balanced scorecard: Measures that drive performance. Harvard Business Review, 71-79.

Kasurinen, T. (2002). Exploring management accounting change: the case of balanced scorecard implementation. Management Accounting Research, 13(3), 323-343. https://doi.org/doi.org/10.1006/mare.2002.0191

Lenz, R., \& Hahn, U. (2015). A synthesis of empirical internal audit effectiveness literature pointing to new research opportunities. Managerial Auditing Journal, 30(1), 5-33. https://doi.org/doi.org/10.1108/MAJ-08-2014-1072

Lorange, P., Scott Morton, M. F., \& Ghoshal, S. (1986). Strategic control system. St. Paul, West Publishing.

Lorino, P. (2001). Le Balanced Scorecard revisité: dynamique stratégique et pilotage de performance, Actes du Congrès de l'Association Francophone de Comptabilité, Metz.

Meyssonnier, F., \& Rasolofo-Distler, F. (2008). Le contrôle de gestion entre performance économique et responsabilité globale: les cas d'une Entreprise Sociale pour l'Habitat. Comptabilité-Contrôle-Audit, December, 107-124.

Meyssonnier, F., \& Rasolofo-Distler, F. (2011). Balanced scorecard et pilotage de la responsabilité sociale de l'entreprise. Retour d'expérience. Revue Française de Gestion, 211, 81-92.

Naro, G. (1998). La dimension humaine du contrôle de gestion: la recherche anglo-saxonne sur les aspects comportementaux de la gestion budgétaire. Comptabilité-Contrôle-Audit, 2(4), 45-69.

Naro, G., \& Travaillé, D. (2011). Le Balanced Scorecard à l'épreuve de l'expérience, dossier. Revue Française de Gestion, 37(211).

Newman, W. H. (1975). Constructive control. N.J.: Prentice-Hall, Englewood Cliffs.

Nguyen, T. T., Mia, L., Winata, L., \& Chong, V. K. (2017). Effect of transformational-leadership style and management control system on managerial performance. Journal of Business Research, 70, 202-213. https://doi.org/doi.org/10.1016/j.jbusres.2016.08.018

Pekkola, S., Saunila M., \& Rantanen H. (2016). Performance measurement system implementation in a turbulent operating environment. International Journal of Productivity and Performance Management, 65(7), 947-958. https://doi.org/doi.org/10.1108/IJPPM-01-2015-0018

Phyrr, P. A. (1973). Zero-base Budgeting. Harvard Business Review.

Popoli. P. (2002). La dimensione strategica del controllo di gestione. Italy, Torino: Giappichelli.

Rockart, J. F. (1979). Chief executives define their own data needs. Harvard Business Review, March/April.

Shank, J. K., \& Govindarajan V. (1989). Strategic cost analysis. The new tool for competitive advantage. Illinois: Irwin, Homewood.

Simons, R. L. (1995). Levers of control. how managers use innovative control systems to drive strategic renewal. Boston: Harvard Business School Press.

Trébucq, S. (2011). Le balanced scorecard en France. Un outil de communication encore incompris. Revue Française de Gestion, 211, 131-143.

Tucker, B., Thorne, H., \& Gurd, B. (2009). Management control and strategy - What's been happening. Journal of Accounting Literature, 28(2), 123-163.

\section{Copyrights}

Copyright for this article is retained by the author(s), with first publication rights granted to the journal.

This is an open-access article distributed under the terms and conditions of the Creative Commons Attribution license (http://creativecommons.org/licenses/by/4.0/). 